REVIEW ARTICLE

\title{
PhaRmaceutical DiluENTS AND Their UNWANTED EFFECTS: A REVIEW
}

\author{
Navneet Nagpal ${ }^{1 *}$, Parmpal Kaur ${ }^{1}$, Rajiv Kumar ${ }^{1}$, Sandeep Rahar ${ }^{2}$, Ravi Dhawan ${ }^{3}$ and \\ Manisha Arora ${ }^{2}$
}

${ }^{1}$ Department of Pharmaceutics, ${ }^{2}$ Department of Pharmaceutical Chemistry, ${ }^{3}$ Department of Pharmacology, Khalsa College of Pharmacy, Amritsar-143001, Punjab, India

${ }^{*} E$-mail: n.nagpal721@gmail.com

Tel.: +919316849394.

Received: Apr 15, 2016 / Revised: Aug 07, 2016 / Accepted: Aug 08, 2016

\begin{abstract}
Diluents are chemically inactive excipients, mostly used to make up the required bulk of solid dosage form and used up to $80 \%$ in a formulation. Various studies reported that diluents used in the solid dosage forms shows unwanted effects in body on long term and some time in short duration therapy. So, it is necessary to study the unwanted effects of diluents by researchers and production chemists before preparation of a pharmaceutical formulation to reduce the unwanted actions. Present review provides toxicological data of commonly used pharmaceutical diluents and summarizes the unwanted effects of pharmaceutical diluents on public health.
\end{abstract}

Key words: Diluents, Solid dosage form, Tablets, Unwanted effects.

\section{INTRODUCTION}

Diluents or fillers are pharmaceutical ingredients which lack pharmacological activity but are desirable or necessary in pharmaceutical preparations. Diluents comprise of heterogeneous groups of substances, designed to make up the required bulk of the tablet when the drug dosage itself is inadequate to produce the bulk (Nahata, 2009). In order to facilitate tablet handling during manufacture and to achieve targeted content uniformity, the tablet size should be kept above 2-3 $\mathrm{mm}$ and weight of tablet should be above $50 \mathrm{mg}$. The range of diluent may vary from $5-80 \%$ in a pharmaceutical formulation (Pandey et al 2009). Diluents are often added to tablet formulation for secondary reason like to provide better tablet properties such as, to allow direct compression, provide improved cohesion, enhance flow and adjust weight of tablet as per die capacity (Chaudhari and Patil, 2012).

Ideally Diluents should not show any effect on the other excipients used in the formulation
(Allen, 2000). Diluents should be able to mill into small sized when needed (Steinberg et al 2001). It should not support microbial growth in the dosage form, should not affect the dissolution of the product, should not interfere with the bioavailability of active ingredients. It should not affect the pharmacological activity of active ingredients (Fathima et al 2011).

\section{Classification of diluents}

Diluents are classified on the basis of chemical nature and solubility:

\section{Chemical nature}

Diluents are further divided into three subtypes on the basis of their chemical structure: as organic, inorganic and co-processed.

\section{Organic materials}

Carbohydrates and modified carbohydrates are the major examples of this category i.e. lactose, starch and pre-gelatinized starch, sucrose, mannitol, sorbitol, powdered and 
microcrystalline cellulose (Vaidya and Avachat, 2011).

\section{Inorganic materials}

These materials are also used commonly in pharmaceutical industries now a days. Calcium phosphates i.e. anhydrous Dibasic Calcium phosphate, dibasic calcium phosphate and tribasic calcium phosphate are main examples of this category (Vaidya and Avachat, 2011).

\section{Co-processed diluents}

Co-processed diluents are prepared from combination of two or more diluents by an appropriate process. The product thus formed are physically modified in such a way that product do not lose their stability and chemical nature. e.g. Sugartabr, Emdex (Gohel, 2005).

Diluents are also divided into water insoluble and water soluble:

\section{Water insoluble diluents}

Examples of water insoluble diluents are starch, powdered cellulose, microcrystalline cellulose and calcium phosphate etc.

\section{Water soluble diluents}

Lactose, sucrose, mannitol, sorbitol etc. (Gohel, 2005).

\section{Unwanted effects of mostly used diluents Sucrose}

Sucrose is a disaccharide in nature and used as a sweetening agent. It is used even in larger amount as a diluent/sweetener in tablets and liquids (Allen et al 2004). Sucrose is absorbed when it get hydrolysed into glucose and fructose in small intestine. Sucrose is excreted unchanged in urine when given by IV route (Hill et al 1988). Sucrose causes a decrease in dental plaque $\mathrm{pH}$, dissolving tooth enamel and promoting dental caries and risk in patients having hereditary problems i.e. fructose intolerance, glucosegalactosemal-absorption, or sucrose-isomaltase insufficiency (Ali et al 1998).

\section{Lactose}

Lactose is widely used as an excipient in pharmaceutical manufacturing as a filler or diluent in tablets, capsules and to give bulk to powders (Figure 1). Lactose has no reaction with most drugs, whether it is used in hydrous or anhydrous form (Lachman et al 1987). Lactose is a disaccharide that consists of galactose and glucose molecules bonded through a $\beta 1-4$ glycosidic linkage. The enzyme lactasephlorizin hydrolase, more commonly known as lactase, is responsible for the hydrolysis of lactose to the monosaccharides glucose and galactose (Ursino et al 2011). Lactase activity is high during infancy but in adult life, it is at a variable level, determined by genetic predisposition, ethnicity, gastrointestinal disorders or infections (Heyman, 2006).

Adverse reactions to lactose are largely attributed to "lactose intolerance (Li)", which occurs in persons with a deficiency of the intestinal enzyme lactase (Pawłowska et al 2016). The primary form of adult-type hypolactasia is an autosomal recessive condition resulting from the physiological decline in activity of the lactase enzyme in intestinal cells after weaning. The secondary form of lactose intolerance occurs in individuals with low lactase level, any quantity of lactose that is ingested is not completely hydrolysed (Campbell et al 2005).
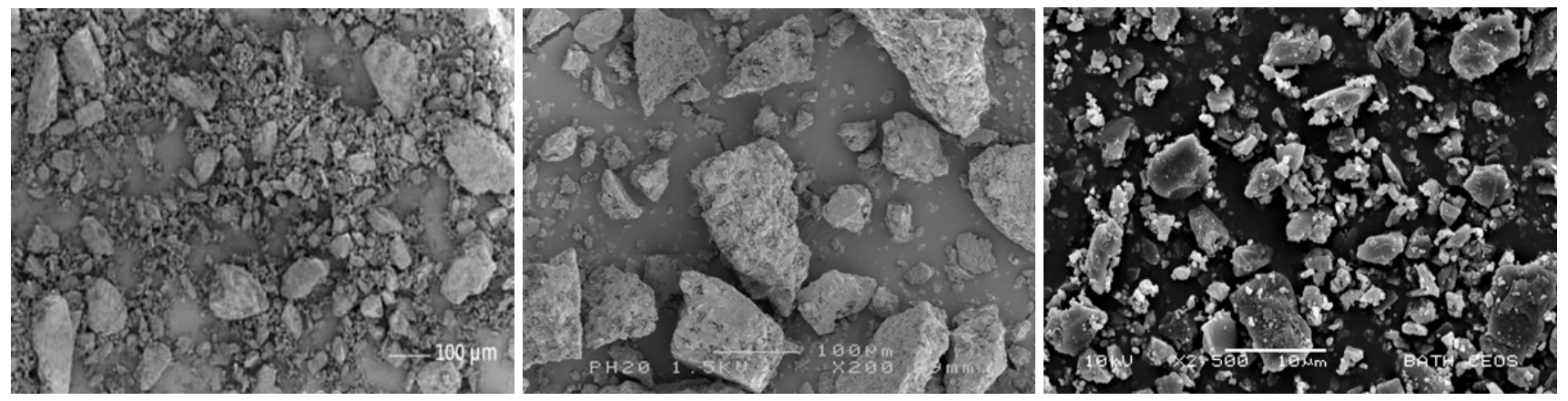

Fig. 1. SEM images of pharmaceutical diluent - lactose

As a consequence, there is a large production of gases such as hydrogen, methane as well as small peptides and toxins due to bacterial metabolization in large intestine. These gases cause abdominal and systemic symptoms including stomach cramps, bloating, flatulence, 
diarrhoea, muscle cramps and headache. Moreover, the unabsorbed lactose raises the osmotic pressure in the colon, preventing water re-absorption and causing laxative effect (Eadala et al 2009).

In two studies, approximately $10-20 \%$ of lactose-intolerant individuals showed clinical symptoms of intolerance after ingestion of 3-5 g of lactose. In one of these studies, $75 \%$ of the subjects had symptoms with $12 \mathrm{~g}$ of lactose (Arola, 1994). In theother study, 8 out of 13 individuals developed diarrhoea after the administration of $20 \mathrm{~g}$ of lactose, and 9 out of 13 after the administration of $25 \mathrm{~g}$ (Arola and Tamm, 1994). Others consider the safety limit to be as low as $5 \mathrm{~g}$ (Lomer et al 2008).

Most patients with lactose intolerance can ingest upto $12 \mathrm{~g}$ of lactose before reporting symptoms (Suarez et al 1995). In some cases the ingestion of $400 \mathrm{mg}$ of lactose from oral medications does not cause a significant difference in breath or in the severity of gastrointestinal symptoms compared to placebo (Montalto et al 2008). Lactose ingestion causes the following three main side effects:

\section{Flatulence}

If sufficient lactose enters the colon, the subject may experience symptoms of abdominal pain, bloating, excess flatulence, and diarrhea, a condition known as lactose intolerance (Hammer et al 1996).

\section{Nausea}

Nausea is the side effect of ingesting lactose when the body has intolerance for it. From the irritation in the body, the sensation of having an urge to vomit, results in the nausea (Pettifor and Hansen, 1974).

\section{Malnutrition}

It occurs as the side effect of lactose ingestion. Malnutrition is condition which show impact on both physical and mental health because of the lack of nutrients necessary to maintain health. Malnutrition can lead to weight loss, fatigue, dizziness, swollen and bleeding gums, muscle and bone weakness, and immune deficiency (Verma and Saxena, 1980).

\section{Mannitol}

Mannitol is also widely used as an excipientin pharmaceutical preparations. It is frequently used as a diluent in chewable and dispersible tablets. Mannitol is comparatively less cariogenic than sugars (McNeill, 1985).

In some case hypersensitivity reactions are reported after the intravenous infusion of $10 \%$ or $20 \%(w / v)$ mannitol solution. These anaphylactic reactions seem to be caused by direct action of mannitol at hyperosmolar concentrations on mast cells in a limited number of subjects (Hegde and Venkatesh, 2004).

When used orally, the absorption of mannitol is not higher than 20\%. Mannitol shows the unwanted effects similar to the sorbitol and other polyalcohol and it may also show impact on gastrin emptying rate and intestinal transit time. Mannitol causes the diarrhoea after the oral administration (Lamb and Keogh, 1979).

A number of adverse reactions to mannitol have been reported, primarily following the therapeutic use of $20 \% \mathrm{w} / \mathrm{v}$ aqueous intravenous infusions (Rowe et al 2009). The quantity of mannitol used as an excipients is considerably less than that used therapeutically and is consequently associated with a lower incidence of adverse reactions. However, allergic, hypersensitive-type reactions, cardiac injury and apoptosis in kidney and heart may occur when mannitol is used as an excipient (Zhang et al 1999).

\section{Methyl cellulose}

Methylcellulose is the organic material used as a diluent in the pharmaceutical formulation. It is the cellulose derivative. On the long term use as a diluent in the pharmaceutical formulation it causes the various side effects (Duro et al 2002). Mostly it causes the abdominal fullness. It also causes the severe allergic reactions (rash, hives, itching, difficulty inbreathing, tightness in the chest, swelling of the mouth, face, lips or tongue) chest pain, difficulty swallowing, nausea, rectal bleeding, stomach pain, and vomiting (Edes et al 1990).

\section{Dicalcium phosphate}

Dicalcium phosphate (DCP) is a combination of positively charged particles of calcium and negatively charged particles of hydrogen phosphate which is interchangeable with the phosphate in the body. Long term use of DCP results in upset in the balance of phosphates and other chemicals in the body. According to the material safety data sheet, the powdered form of DCP may irritate skin. Prolonged skin contact may lead to dry or chapped skin. People with an allergy to DCP could develop contact dermatitis, a specific allergic reaction characterized by 
redness, swelling or itching on skin areas that come into contact with an irritating substance (Grobben et al 2006). In severe cases, this allergic reaction may spread elsewhere, even to areas that have not been in direct contact with dicalcium phosphate. Inhalation of dicalcium phosphate powder may irritate the lung and nasal passage and causes cough and sneezing (Osterberg and See, 2003).

High level of this diluent may upset the gastrointestinal system. It causes the nausea, vomiting, loss of appetite, constipation, stomach pain, dry mouth and increase urination (Wasserman, 2013).

\section{Calcium carbonate}

It is the principal form of calcium found in bovine milk and blood. It is used in the variety of dental products for remineralisation and as a diluent in some medications where it gives the tablet a grey colour in the absence of colouring agents. It causes the constipation, allergic reaction (reshes, itching, tightness in chest, swelling of the mouth, face, lips) confusion, increased urination, loss of appetite, mood changes, nausea, stomach pain, weekness and vomiting (Clemens and Feinstein, 1977).

Rare cases of calcium carbonate gallstones have been reported in the paediatric (Frithz et al 1991). Prolonged ingestion of large amount of calcium carbonate results in the milk alkali syndrome and calcinosis. The milk alkali syndrome is characterized by the triad of hypercalcemia, metabolic alkalosis and renal insufficiency. Metabolic side effects included hypercalcemia and hypophosphatemia (Ullion and Linas, 1988).

\section{Polyethylene glycol}

Polyethylene glycol used as an inactive ingredient in the pharmaceutical industry. At the high doses causes the teratogenic activity which increases the fetal loss, decrease body weight and malformation (Baldrick, 2000).

\section{REFERENCES}

Ali M, Rellos P, Cox TM. Hereditary fructose intolerance. J. Med. Genet.1998;35:353-65. [DOI: 10.1136/jmg.35.5.353]

Allen LV Jr. Featured excipient: capsule and tablet diluents. Int. J. Pharm. Comp. 2000;4(4):306-25.

Allen LV Jr, Popovich NG, Ansel HC. Ansel's Pharmaceutical Dosage Forms and Drug Delivery Systems, $8^{\text {th }}$ edition, Lippincott Williams \& Wilkins, Wolters Kluwer, Philadelphia, United States, 2004.

Arola H. Diagnosis of hypolactasia and lactose malabsorption. Scand. J. Gastroenterol. (Suppl.) 1994;29(202): 26-35. [DOI: 10.3109/00365529409091742]

\section{Dextrose}

Dextrose is a common name for the ubiquitous sugar molecule, glucose. Over use of the dextrose can result in some very undesirable side effects. Too much dextrose can actually lead to a paradoxical effect in individuals without diabetes (Oppelt et al 2015). If blood sugar rises very high very quickly, the pancreas secretes very large quantities of insulin. This signals the cells to take up blood sugar quickly, since hyperglycaemia is damaging to the tissues. As a result of the pancreatic over reaction to very high blood sugar, the cell can take up too much blood sugar, leading to hypoglycaemia. High dextrose consumption also results in hyperglycaemia, if untreated, can lead to tissue damage, coma and death. One other side effect of excess dextrose consumption is an increase in body fat (Martin and Lewis, 2004).

To reduce the unwanted effects of the diluents there is a deemed needs to establish new herbal pharmaceutical diluents which are inert or provide their nutraceutical value for treating such disease.

\section{CONCLUSION}

Information related to pharmaceutical diluents with known potential side effects is important in clinical practice, in particular for patients suffering from disorders that could be aggravated by the ingestion of these substances. Diluents being an indispensible component of some dosage forms, they must be evaluated for their safety and stability. The safety assurance of diluent helps the formulator to design an effective and safe dosage form with the use of efficient and safe diluents. It seems to be necessary to improve the information about the diluents in patient information leaflets. Although the safety profile of some diluents discussed in this review has already well established, paying attention to pharmaceutical diluents and their safety issues is an indispensable initial step to the success of drug products.

Arola H, Tamm A. Metabolism of lactose in the human body. Scand. J. Gastroenterol. (Suppl.) 1994;29(202):21-5. [DOI: 10.3109/00365529409091741]

Baldrick P. Phamaceutical excipient development: the need for preclinical guidance. Regul. Toxicol. Pharmcol. 2000; 32(2):210-8. [DOI: 10.1006/rtph.2000.1421]

Campbell AK, Waud JP, Matthews SB. The molecular basis of lactose intolerance. Sci. Prog. 2005;88(3):157-202.

Chaudhari SP, Patil PS. Pharmaceutical excipients: a review. Int. J. Adv. Pharm. Biol. Chem. 2012;1(1):21-34.

Clemens JD, Feinstein AR. Calcium carbonate and 
constipation: a historial review of medical mythopoeia. Gastroenterol. 1977;72(5):957-61. [DOI: 10.1016/S00165085(77)80220-5]

Duro D, Rising R, Cedillo M, Lifshitz F. Association between infantile colic and carbohydrate malabsorption from fruit juices in infancy. Pediatrics 2002;109(5):797-805. [DOI: 10.1542/peds.109.5.797]

Eadala P, Waud JP. Matthews SB, Green JT, Campbell AK. Quantifying the 'hidden' lactose in drugs used for the treatment of gastrointestinal conditions. Aliment. Pharmacol. Ther. 2009;29(6):677-87. [DOI: 10.1111/j.13 65-2036.2008.03889.x]

Edes TE, Walk BE, Austin JL. Diarrhea in tube-fed patients: feeding formula not necessarily the cause. Am. J. Med. 1990;88(2):91-3. [DOI: 10.1016/0002-9343(90)90454-L]

Fathima N, Mamatha T, Qureshi HK, Anitha N, Venkateswara Rao J. Drug-excipient interaction and its importance in dosage form development. J. Appl. Pharm. Sci. 2011;01(06):66-71.

Frithz G, Wictorin B, Ronquist G. Calcium-induced constipation in a prepubescent boy. Acta Paediatr. Scand. 1991;80(10):964-5.

Gohel MC, Jogani PD. A review of co-processed directly compressible excipients. J. Pharm. Pharm. Sci. 2005;8(1): 76-93.

Grobben AH, Steele PJ, Somerville RA, Taylor DM. Inactivation of transmissible spongiform encephalopathy agents during the manufacture of dicalcium phosphate from bone. Vet. Rec. 2006;158(11):361-6.

Hammer HF, Petritsch W, Pristautz H, Krejs GJ. Evaluation of the pathogenesis of flatulence and abdominal cramps in patients with lactose malabsorption. Wien. Klin. Wochenschr. 1996;108(6):175-9.

Hegde VL, Venkatesh YP. Anaphylaxis to excipient mannitol: evidence for an immunoglobulin E-mediated mechanism. Clin. Exp. Allergy 2004;34(10):1602-9. [DOI: 10.1111/J.13 65-2222.2004.02079.x]

Heyman MB. Lactose intolerance in infants, children, and adolescents. Pediatrics 2006;118(3):1279-86. [DOI: 10.15 42/peds.2006-1721]

Hill EM, Flaitz CM, Frost GR. Sweetener content of common pediatric oral liquid medications. Am. J. Hosp. Pharm. 1988;45(1):135-42. [DOI: 10.1016/S0031-3955(05)702 56-X]

Lamb JD, Keogh JA. Anaphylactoid reaction to mannitol. Can. Anaesth. Soc. J. 1979;26(5):435-6. [DOI: 10.007/BF0 3006461]

Lachman L, Liberman HA, Joseph KL.The Theory and Practice of Industrial Pharmacy, Varghese, Mumbai, 1987.

Lomer MC, Parkes GC, Sanderson JD. Review article: lactose intolerance in clinical practice-myths and realities. Aliment. Pharmacol. Ther. 2008;27(2):93-103. [DOI: 10.11 11/J.1365-2036.2007.03557.x]

Ursino MG, Poluzzi E, Caramella C, De Ponti F. Excipients in medicinal products used in gastroenterology as a possible cause of side effects. Regul. Toxicol. Pharmcol. 2011;60(1):93-105. [DOI: 10.1016/j.yrtph.2011.02.010]

Martin GS, Lewis CA. Fluid management in shock. Semin.
Respir. Crit. Care Med. 2004;25(6):683-93. [DOI:10.105 5/s-2004-860982]

McNeill IY. Hypersensitivity reaction to mannitol. Drug Intell. Clin. Pharm. 1985;19(7-8):552-3.

Montalto M, Gallo A, Santoro L, D'Onofrio F, Curigliano V, Covino M, Cammarota G, Grieco A, Gasbarrini A, Gasbarrini G. Low-dose lactose in drugs neither increases breath hydrogen excretion nor causes gastrointestinal symptoms. Aliment. Pharmacol. Ther. 2008;28(8):1003-12. [DOI: 10.1111/J.1365-2036.2008.0 3815.x]

Nahata MC. Safety of "inert" additives or excipients in paediatric medicines. Arch. Dis. Child. Fetal Neonatal Ed. 2009;94(6):F392-3. [DOI: 10.1136/abc.2009.160192]

Osterberg RE, See NA. Toxicity of excipients - a food and drug administration perspective. Int. J. Toxicol. 2003; 22(5):377-80. [DOI: 10.1177/109158180302200507]

Pandey VP, Venkateswara Reddy K, Amarnath R. Studies in diluents for formulation of tablets. Int. J. Chem. Sci. 2009; 7(4):2273-7.

Pawłowska K, Umławska W, Iwańczak B. The impact of lactose malabsorption and lactose intolerance on dairy consumption in children and adolescents with selected gastrointestinal diseases. Pediatr. Pol. 2016;91(3):192-8. [DOI: 10.1016/j.pepo.2016.03.013]

Pettifor JM, Hansen JD. Letter: lactose intolerance in San populations. Br. Med. J. 1974;3(5924):173. [DOI: 10.337 8/027.081.0609]

Rowe RC, Sheskey PJ, Quinn ME. (eds.) Handbook of Pharmaceutical Excipients. $6^{\text {th }}$ edition, Pharmaceutical Press, London, 2009.

Oppelt SA, Sennott EM, Tolan DR. Aldolase-B knockout in mice phenocopies hereditary fructose intolerance in humans. Mol. Genet. Metab. 2015;114(3):445-50. [DOI: 10. 1016/j.ymgme.2015.01.001]

Steinberg M, Blecher L, Mercill A. From inactive ingredients to pharmaceutical excipients. Pharm. Technol. 2001;25 (7):62-4.

Suarez FL, Savaiano DA, Levitt MD. Review article: the treatment of lactose intolerance. Aliment. Pharmacol. Ther. 1995;9(6):589-97. [DOI: 10.1111/J.1365-2036.199 5.tb00427.x]

Ullian ME, Linas SL. The milk-alkali syndrome in pregnancy. case report. Miner. Electrolyte Metab.1988;14(4):208-10.

Vaidya MP, Avachat AM. Investigation of the impact of insoluble diluents on the compression and release properties of matrix based sustained release tablets. Powder Technol. 2011;214(3):375-81. [DOI: 10.1016/j.po wtec.2011.08.035]

Verma M, Saxena S. Lactose intolerance in children with protein-energy malnutrition. Indian J. Pediatr. 1980; 47(4):273-7. [DOI: 10.1007/BF02831314]

Wasserman R. Negative effects of dicalcium phosphate, 2013. (http://www.livestrong.com)

Zhang J, Duarte CG, Ellis S. Contrast medium- and mannitolinduced apoptosis in heart and kidney of SHR rats. Toxicol. Pathol. 1999;27(4):427-35.

http://www.dfepharma.com/en/excipients/lactose 